\title{
Telecommuting for Original Cataloging at the Michigan State University Libraries
}

\section{Leah Black and Colleen Hyslop}

\begin{abstract}
Telecommuting has become a popular option in recent years for workers in the business world seeking relief from lengthy, stressful commutes and workplace distractions. Working conditions in library technical services departments can be a problem for catalogers in need of a quiet work environment. As technological advances continue to influence library cataloging applications, creating cataloging records from work sites outside the library is an attractive option for addressing library work environment concerns. Based on a successful program for indexers at the National Agriculture Library, a proposal for an experimental telecommuting program for original cataloging in a university library was developed and tested.
\end{abstract}

elecommuting arrangements in the business world have become common in recent years. Increasingly lengthy commutes on crowded freeways, sophisticated technological capabilities combined with employee needs, and environmental issues have prompted companies to develop and implement programs allowing employees to work from their homes. Computer links between office and home and electronic mail systems are among the methods employed to enable the at-home worker to communicate with the office. While some businesses allow workers to telecommute five days a week, others combine in-office with at-home work arrangements enabling the employee to work from home some portion of each week.

While telecommuting arrangements in libraries are not so prevalent as those in the business world, to some extent because some library activities require staffing at a public desk or handling of materials on-site, technological advances in library applications have made the idea of telecommuting in library work increasingly attractive. Staffing issues and the increasing need for flexibility may be the catalysts that force libraries to examine telecommuting arrangements as one means of addressing these concerns. In addition, successful programs such as the National Agriculture Library's extremely popular Flexiplace option now provide valuable precedent.

At the Michigan State University Libraries, a need for flexible arrangements providing varied workplace choices has been identified as a means of enhancing employee satisfaction. Since the cataloger may now search online sources such as OCLC and library online catalogs for possible classification numbers and subject headings, and since printed

Leah Black is Catalog Librarian at Michigan State University Libraries, East Lansing, Michigan 48824; e-mail: 20676lcb@msu.edu. Colleen Hyslop is Assistant Director for Technical Services at Michigan State University Libraries, East Lansing, Michigan 48824; e-mail: 20676cfh@msu.edu. 
tools such as classification schedules and subject headings are being converted to machine-readable online formats, it seemed reasonable to pursue the possibility that a process for creating cataloging records from work sites outside the library could be developed. Interest on the part of one cataloger, with substantial support from Technical Services administration, prompted a request for funding to pursue the development and implementation of a telecommuting pilot project for cataloging. Library administrators chose original cataloging for the test because professional staff composed the unit, and the structure and scheduling of original cataloging was appropriate for the type of experiment under consideration. The unionized environment for support staff made the program design more complicated, so copy cataloging was not considered for the pilot test.

In preparation for the development of the telecommuting plan for the Michigan State University Libraries, staff at the National Agriculture Library participating in the Flexiplace program were interviewed during a two-day visit in May 1993. Participants and supervisors representing both indexing and public services staff were included. Issues for telecommuters were identified through a literature search prior to the interviews and included communication difficulties, isolation, misconceptions about telecommuting on the part of coworkers, and difficulties maintaining an appropriate separation between work and home life. Similarly, library administrators' concerns included supervisory and performance evaluation issues, scheduling difficulties for other staff members, liability, budgets and equipment, procedural issues, and criteria for participating. Using a list of questions developed and distributed prior to the visit, the interviews provided a wealth of information about the issues and problems associated with developing and implementing a telecommuting program. The enthusiasm of the National Agriculture Library participants and their willingness to share both their experiences and program documentation impressed the interviewers.

They presented the proposal for telecommuting developed in consultation with various library units, including Systems and the Original Catalogers Team, to the Libraries' administration for consideration in February 1994. The program was designed as an experimental project for one original cataloger to test the following basic telecommuting assumptions:

- That a quieter, less distracting cataloging setting would have a positive impact on cataloging workflow, productivity, and costs;

- That the level of employee satisfaction would be enhanced by work-style choices;

- That library telecommunications' setup and operations could be configured satisfactorily;

- That intralibrary communications would not be hindered; and

- That other librarians might benefit from telecommuters' experiences.

Long-term goals of a permanent telecommuting program were also identified:

- To provide work environment choices for librarians;

- To make the best use of technological advancements and capabilities in a library setting;

- To help alleviate overcrowded working conditions in Technical Services;

- To provide incentives for employees to remain with the university, and

- To explore the applicability of telecommuting experiences in the business world to a library setting.

The proposal document included: a program description, a memorandum of understanding outlining program guidelines and a library telecommuting policy, and defined responsibilities for the participant and the library in areas such as scheduling, time frame, librarysupplied equipment use, liability, and performance evaluation. The pilot program allowed the telecommuting cataloger to work from home up to two days per week, returning to the library for the remainder of the workweek. A telecommuting schedule mutually agreeable to 
the participant and the Original Catalogers Team was developed and included on the team's calendar. Cataloging records were created by the telecommuter offline, using the Cataloging MicroEnhancer Plus software. Original cataloging procedures at the MSU Libraries specify direct input of cataloging records into OCLC, but the added cost of dial-access OCLC use from an off-campus work site was prohibitive in the experimental stages. While Internet access to OCLC was highly desirable, the Libraries' Systems staff was unable to devote the time necessary for implementation of this access method.

The pilot program allowed the telecommuting cataloger to work from home up to two days per week, returning to the library for the remainder of the workweek.

Equipment requirements were identified in consultation with the Libraries' Systems staff, and the telecommuter's personal equipment was used since it met the basic program requirements. The program description provided a mechanism for original catalogers without personal computers at home to participate using library equipment, but this approach was not tested since no original cataloger in that circumstance expressed an interest in participating.

The Libraries supplied the software necessary for the project, including the Cataloging MicroEnhancer Plus for offline cataloging record creation, OCLC's Passport for dial-access OCLC use, and Kermit for access to the Libraries' online catalog and the university's Gopher system. Word processing software was already available, allowing the telecommuter flexibility to work on other assigned duties from home. The telecommuter installed the software successfully and did not require assistance from the Libraries' Systems staff.

Program expenses were limited to purchase of the CATME+ software and dial-access OCLC fees. Since the latter was an added expense for the MSU Libraries, use of dial-access to OCLC was judicious. Careful presearching using dedicated-line OCLC terminals in the library met most searching needs, and the dial-access connection was used from home most often for quick authority searches.

The telecommuter prepared draft cataloging records which required access to the piece being cataloged and selected cataloging tools. The uncataloged materials were carried home each week by the telecommuter, and copies of AACR2 and OCLC formats were available to the telecommuter at both in-library and athome work sites. The telecommuter was able to complete drafts for ten to twelve items in a typical at-home workday. Since the telecommuting cataloger worked from home no more than two days per week, materials being cataloged were not absent from the library for long periods of time. Tentative subject headings and call numbers were determined at home by access to the Libraries' online catalog (MAGIC), OCLC, and other libraries' online catalogs, with final assignments made later, after consulting $\mathrm{LCSH}$ and the classification schedules in the library. Records were uploaded into OCLC after completion upon return to the library. Problems which required consultation with colleagues or reference sources in the library were handled by telephone or electronic mail contacts, or by setting the piece aside for later completion.

Access to voice and electronic mail ensured effective communication channels between the telecommuting cataloger and other library staff members and colleagues. Each cataloger at the MSU Libraries has a private work telephone number with voice mail capability, so the telecommuter was able to easily retrieve messages from home and in-library staff were not burdened with recording and transferring messages to the telecommuter at home.

Evaluation criteria for the six-month experiment included a statement from the telecommuter addressing work environment issues, cataloging workflow and productivity, communication issues, 
effect on committee assignments and other noncataloging duties, telecommunications operation, effect on cooperative projects and general workflow, and a comparison of statistics for the pilot project period and the six months preceding the experiment.

The pilot program was implemented June 1, 1994, and officially concluded November 30,1994. An evaluation of the project is under way. Preliminary conclusions indicate the process as designed was successful and reasonably efficient, with both the library and the telecommuter pleased with the program's outcome. The telecommuter's at-home office arrangement proved to be a comfortable improvement over the main library's crowded and busy Technical Services department. Original cataloging output increased for the test period, although an increase in productivity was not considered a criterion for success. The cataloging workflow as designed was adequate, although the interruption in the workflow required by lack of access to LCSH and classification schedules at home was a greater problem than anticipated. The telecommuter reported occasional feelings of isolation when working at home, and concluded that while the chatter of co-workers and background noises such as ringing telephones can hinder concentration, the social nature of the in-library environment can be a comfort as well. Telecommunications links during the test period were trouble-free; at no time was the telecommuter unable to work from home due to lack of access to needed systems.

For the cataloger disadvantaged by a noisy working environment, cataloging from home provides a more controlled and individually suitable work setting. Away from the distractions inherent in an overly social work environment, a cataloger's work output is potentially enhanced. However, online access to a wider range of cataloging resources is necessary to realize the full potential of the telecommuting process. Access to OCLC via the Internet is also critical. Until the cataloging record can be completed and input from the home work site, the process will have achieved only a limited degree of success.

The pilot test was successful in proving that original cataloging can be accomplished from a home work site, but expansion and improvement in technological access are necessary for telecommuting to be considered a strong alternative to a traditional cataloging setting at Michigan State University. It is important that an effort be made to realize the potential of this alternative. In a recent journal article on telecommuting in a library environment, Delores Meglio clearly outlines the advantages of such arrangements:

Computers, modems, hard disks, CD-ROM, and other technologies have provided the means of doing work away from the library or corporate headquarters. New technology allows companies to develop effective telecommuting programs with enormous benefits for both staff and employer. For the employer, it means less employee turnover, less absenteeism, improved morale, increased flexibility, lower overhead costs and increased overall efficiency. For the staffers who work at home, telecommuting allows greater flexibility of and control over their schedules, ... ability to pursue other interests, and a more desirable environment. In this situation, both the employee and employer gain.*

A successful telecommuting program for cataloging at the Michigan State University Libraries could reduce staff crowding in the main library building, boost morale, reduce environmental pollution and parking congestion, provide a less stressful work environment, take advantage of technology, and offer a variety of positive work options to catalogers.

* Delores Meglio, "Implications of Telecommuting in a Library Environment," Library Administration and Management 5, no. 1 (Winter 1991): 30-33. 


\section{SELECTED BIBLIOGRAPHY}

"At Home Work Uncommon in Libraries." Library Personnel News 4, no. 1 (Winter 1990): 2.

Basch, Reva. "A Day in the Life of an Electronic Cottager." Electronic Library 10, no. 3 (1992): 131-32.

Caudron, Shari. "Working at Home Pays Off." Personnel Journal 77 (Nov. 1992): 42-49.

Entlich, Richard, William Fenwick, and Dongming Zhang. "Enhancing the Processing Environment: The Development of a Technical Services Workstation." Information Technology and Libraries 11 (Dec. 1992): 324-38.

Filipczak, Bob. "Telecommuting, a Better Way to Work?" Training 29 (May 1992): 53-61.

Joseph, Patricia A. "Telecommuting and Social Change." 1984 Challenges to an Information Society: Proceedings of the 47th ASIS Annual Meeting (1984): 23-25; Luce, Richard E., and Susan Hartman. "Telecommuting to Work: Using Technology to Work at Home." Library Hi Tech 2, no. 4 (1984): 79-83.

O'Malley, Christopher. "Top 10 Home Office Misconceptions." Personal Computing 13 (Nov. 1989): 67-70.

Human Resources Committee of the President's Council on Management Improvement, Guidelines for Pilot Flexible Workplace Arrangements. 1990.

Sapon-White, Richard E. "Cataloging Using Internet-accessible Library Catalogs." Technicalities 11, no. 10 (1991): 7-8.

Weiss, Julian M. "Working at Home a Plus for U.S. Agencies." Computer Digest (Sept. 1992): 17.

\section{Use INTERNET to}

\section{UnCover...}

UnCover

6 million articles from 20,000 multidisciplinary periodicals delivered by fax in 24 hours or less
UnCover

Reveal

Electronic TOC service with user profiling
UnCover

Complete

Pre-1989 journals can be ordered online

\section{UnCover SOS}

Order articles by fax, phone, e-mail or post from UnCover's Single Order Source service

\section{The UnCover Company}

E-mail: uncover@carl.org

380 I East Florida Avenue, Suite 200 a Denver, CO 80210 , USA

Phone: I-800-787-7979 a Fax: 303-758-5946

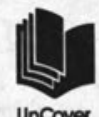

Readmore, Inc.

22 Cortlandt Street

New York, NY 10007

...Articles

Phone: $|-800-22|-3306$

UnCover is a service of Readmore, Inc. 


\section{BLACKWELL}

for

SmartSourcing ${ }^{\text {TM }}$

Full Book Processing

Tables of Contents

Authority Control

FTP MARC Records Worldwide

OCLC PromptCat ${ }^{\mathrm{TM}}$ Provider

Catalog-Ready MARC Records

The LEADER in Bibliographic Services for Over 20 Years

B. H. Blackwell Blackwell North America Oxford Lake Oswego, OR • Blackwood, NJ 